\title{
Frankincense and myrrh and their bioactive compounds ameliorate the multiple myeloma through regulation of metabolome profiling and JAK/STAT signaling pathway based on U266 cells
}

Rumeng Gao ${ }^{1,2+}$, Xiaodong Miao ${ }^{1+}$, Chengjing Sun', Shulan Su*, Yue Zhu', Dawei Qian', Zhen Ouyang ${ }^{2}$ and Jinao Duan ${ }^{1 *}$

\begin{abstract}
Background: Frankincense and myrrh are used as traditional anti-inflammatory and analgesic medicines in China. It has been reported that frankincense and myrrh have significant anti-tumor activities. The present study was designed to investigate the inhibitory efficacy of frankincense ethanol extracts (RXC), myrrh ethanol extracts (MYC), frankincense -myrrh ethanol extracts (YDC), frankincense -myrrh water extracts (YDS) and their main compounds on U266 human multiple myeloma cell line.

Methods: The inhibition effects of cell proliferation was evaluated by MTT assays. Cell culture supernatant was collected for estimation of cytokines. Western blot analysis was designed to investigate the regulatory of JAK/STAT signal pathway. In addition, cell metabolomics based on the ultra-performance liquid chromatography coupled with quadrupole time-offlight mass spectrometry (UPLC/Q-TOF-MS) had been established to investigate the holistic efficacy of frankincense and myrrh on U266 cells. Acquired data were processed by partial least-squares discriminant analysis (PLS-DA) and orthogonal projection to latent structures squares-discriminant analysis (OPLS-DA) to identify potential biomarkers.
\end{abstract}

(Continued on next page)

\footnotetext{
* Correspondence: sushulan1974@163.com; duanja@163.com

${ }^{\dagger}$ Rumeng Gao and Xiaodong Miao contributed equally to this work.

'Jiangsu Collaborative Innovation Center of Chinese Medicinal Resources Industrialization, Jiangsu Key Laboratory for High Technology Research of TCM Formulae, National and Local Collaborative Engineering Center of Chinese Medicinal Resources Industrialization and Formulae Innovative Medicine, Nanjing University of Chinese Medicine, Nanjing 210023, China Full list of author information is available at the end of the article
}

(c) The Author(s). 2020 Open Access This article is licensed under a Creative Commons Attribution 4.0 International License, which permits use, sharing, adaptation, distribution and reproduction in any medium or format, as long as you give appropriate credit to the original author(s) and the source, provide a link to the Creative Commons licence, and indicate if changes were made. The images or other third party material in this article are included in the article's Creative Commons licence, unless indicated otherwise in a credit line to the material. If material is not included in the article's Creative Commons licence and your intended use is not permitted by statutory regulation or exceeds the permitted use, you will need to obtain permission directly from the copyright holder. To view a copy of this licence, visit http://creativecommons.org/licenses/by/4.0/ The Creative Commons Public Domain Dedication waiver (http://creativecommons.org/publicdomain/zero/1.0/) applies to the data made available in this article, unless otherwise stated in a credit line to the data. 
(Continued from previous page)

Results: RXC, MYC significantly inhibited the proliferation of U266 cells at dose of $25-400 \mu \mathrm{g} / \mathrm{mL}$, YDC and YDS at the dose of 12.5-400 $\mu \mathrm{g} / \mathrm{mL}$. 3-O-acetyl-a-boswellic acid, 3-acetyl-11 keto-boswellic acid and 11-keto-boswellic acid had the most significant anti- multiple myeloma activities in the 10 compounds investigated, therefore these 3 compounds were selected as representatives for Elisa assay and western blotting experiments. All the extracts and active compounds ameliorated the secretion of cytokines and down-regulated the expression of JAK/STAT signaling pathway-related proteins. Comparing RXC, MYC, YDC and YDS-treated U266 cells with vehicle control (DMSO), 13, 8, 7, 7 distinct metabolites and 2, 2, 3, 0 metabolic target pathways involved in amino acid metabolism, lipid metabolism, vitamin metabolism, arachidonic acid were identified, respectively.

Conclusions: Taken together our results suggest that the frankincense and myrrh and their bioactive compounds inhibit proliferation of U266 multiple myeloma cells by regulating JAK/STAT signaling pathway and cellular metabolic profile.

Keywords: Frankincense and myrrh, Multiple myeloma, JAK/STAT signaling pathway, Biomarkers, Metabolomics

\section{Background}

Today, multiple myeloma (MM) is the second most common cancer in hematological malignant disease. More than 12 thousand deaths were estimated in 2018, accounted for $2.1 \%$ of all cancer deaths and the percent surviving 5 years was $50.7 \%$ in 2008-2014, according to epidemiology, surveillance, and end result program (https://seer.cancer.gov/) [1]. The overall efficacy of current conventional therapies for MM, including combined chemotherapy, radiation therapy, stem cell transplantation, new drug treatment, etc., are not ideal. However, the experimental researches on therapeutic effect and mechanism of traditional Chinese medicine on MM have been made a breakthrough.

Frankincense and myrrh, classical traditional Chinese medicine, are commonly used in Chinese medicine as anti-inflammatory and analgesia drugs. Vitro studies have shown that frankincense, which has been commonly believed the efficacy substance is boswellic acid, have anti-inflammatory activity [2], analgesic [3], immunosuppressive and antitumor activities [4]. The main components in myrrh are volatile oils, including monoterpenoid and sesquiterpenoids, having the same effect as frankincense [5-9]. Previous studies have exhibited that the compatibility of frankincense and myrrh have certain impacts against tumors, including Ehrlich ascites [10], prostate cancer cells [11], and breast cancer cells [6], et al. However, there are few studies about the evaluation of the effects on MM and mechanisms.

Owing to the limitation, such as poor repeatability, less quantity of data, and time-consuming of conventional anti-tumor drugs research models, including MTT reduction assay for cellular proliferation, flow cytometry for cellular apoptosis, RT-PCR for gene expression, and Western blot for protein expression [12], the metabolomics has been more and more applied in anti-tumor mechanisms. Metabolomics is one of the newest biology approaches focused on the global metabolic status of the entire organism through non-targeted analysis of metabolites in biological samples and based on the analytical techniques including mass spectroscopy, ${ }^{1} \mathrm{H}$-NMR spectroscopy and liquid chromatography-mass spectroscopy [13]. Notably, cancer is a disease with mitochondrial energy metabolic disorder, which is well recognized as Warburg effect. Therefore, metabolic profiling of cells underlying treatment with anticancer drug candidates is greatly helpful for understanding their action mechanisms.

U266 is a human multiple myeloma cell, and belongs to a suspension cell line, which is the first choice for the study of multiple myeloma diseases in vitro. In this study, we designed to investigate the inhibitory efficacy of Frankincense, Myrrh and their bioactive based on U266 multiple myeloma cells and explain the action mechanism of the anti-multiple myeloma of frankincense and myrrh combining conventional molecular biology with metabolomics.

\section{Methods}

\section{Chemicals and instruments}

U266 human multiple myeloma cells were purchased from the American Type Culture Collection (VA, Catalog No.: CC-Y1527, USA). Fetal bovine serum and RPMI-1640 medium were purchased from Gibco Life Technologies (NY, USA). Methylene blue and dimethyl sulfoxide (DMSO) were purchased from Sigma-Aldrich (MO, USA). IL-6, VEGF ELISA kits were purchased from Nanjing Jiancheng Biotechnology Co., Ltd. (Nanjing, China). JAK1, p-JAK1 STAT3, p-STAT3 and GAPDH antibodies were purchased from Cell Signaling Technology (BSN, USA).

Waters Acquity TM Ultra Performance LC system (Waters, Milford, MA, USA) equipped with a Quattro Micro MS spectrometer and a Waters Xevo TM G2 QTof MS (Waters MS Technologies, Manchester, NH, USA). Deionized water was purified on a Milli-Q system (Millipore, Bedford, MA, USA). Mass Lynx v4.1 workstation was adopted to analyze the data, and Ultra- 
highspeed centrifuge at low temperature (Thermo Scientific, Waltham, MA, USA); DMI3000M microscope (Leica, München, Germany) were used.

Frankincense (lot number 171010) and myrrh (lot number 171108) were purchased from Suzhou Tianling Chinese Medicine Pieces Co., Ltd. (Suzhou, China). Standards 3-O-acetyl--boswellic acid (lot number 20150515), 3 $3 \alpha$-acetyl-20(29)-lupene-24-oic acid (lot number 20150513), $\beta$-boswellic acid (lot number 20150504 ), acetyl $11 \alpha$-methoxy- $\beta$-boswellic acid (lot number 20150519), $3 \alpha$-acetoxy-tirucall-7,24-dien-21oic acid (lot number 20150523), 11-keto- $\beta$-boswellic acid (lot number 20150525), 3-acetyl- $\beta$-boswellic acid (lot number 20150410) ware purchased from Baoji Chenguang Biotechnology Co., Ltd. (Baoji, China) and the purity was greater than $98 \%$. Abietic acid and 2methoxy-8, 11-epoxygermacra-1(10)-7, 11-trien-6-one were laboratory-made and the purity are greater than 98\% determined by UPLC-MS.

\section{Preparation of drug solution}

Ethanol extracts preparation: frankincense, myrrh and frankincense-myrrh pair (1:1 compatibility) were extracted twice with 12 times amount of $95 \%$ ethanol, $2 \mathrm{~h}$ each time. Combined the two supernatants, then evaporated the solvent to obtain each of the prepared samples. Each sample was separately dissolved in 1\% DMSO to prepare $4 \mathrm{mg} / \mathrm{mL}$ of the RXC, MYC, and YDC technical liquid concentrates for storage.

Water extract preparation: frankincense-myrrh pair (1:1 compatibility) was extracted twice with 12 times the amount of water, $2 \mathrm{~h}$ each time. Combined the two supernatants, then evaporated the solvent to obtain each of the prepared samples. The sample was dissolved in water to prepare $4 \mathrm{mg} / \mathrm{mL}$ YDS technical liquid concentrates for storage.

Compounds monomer solution preparation: Each compound monomer was dissolved in $1 \% \mathrm{DMSO}$ to prepare $1 \mathrm{mmol} / \mathrm{L}$ compound monomer technical liquid concentrates for storage.

\section{Anti-proliferative activity}

U266 cells were cultured in RPMI 1640 medium containing 10\% FBS and 1\% antibiotic-antimycotic and maintained in an incubator at $5 \% \mathrm{CO} 2$ and $37^{\circ} \mathrm{C}$ as ATCC described. A total of $2 \times 10^{4}$ cancer cells in growth media were placed in each well of a 96-well plates. After that, various concentrations of RXC, MYC, YDC, YDS $(25,50,100,200$ and $400 \mu \mathrm{g} / \mathrm{L})$ and compounds monomer $(5,10,25,50$ and $100 \mu \mathrm{mol} / \mathrm{L})$ were added in each well, then the cells were cultured for $48 \mathrm{~h}$. Each of the drug groups was evaluated in triplicate. After incubation, $10 \mu \mathrm{L}$ of $0.5 \mathrm{mg} / \mathrm{mL}$ MTT solution was added to each well in the dark and cells were incubated for another $4 \mathrm{~h}$. The supernatant was discarded and $150 \mu \mathrm{L}$ of DMSO was added. Then shaking slightly for 30 min until blue-violet crystals completely dissolved. The absorbance (A) value of each well was measured at $570 \mathrm{~nm}$ by a microplate reader and the cell proliferation inhibition rate was calculated. Each experiment was repeated at least three times. Proliferation inhibition rate $(\%)=(1-$ experimental group A value / control group A value) $\times 100 \%$.

\section{ELISA assay}

IL-6, VEGF kits assay were used to evaluate the change of cytokine. According to the manufacturer's protocols, $2 \times 10^{4}$ cells were placed in each well of a 96-well plates. After treated with 200, 100, $50 \mu \mathrm{g} / \mathrm{mL}$ RXC, MYC, YDC, YDS and 100, 50, $25 \mu \mathrm{mol} / \mathrm{L} \mathrm{BC}$, AKBA, KBA for $48 \mathrm{~h}$ respectively, cell supernatant was collected for Elisa detection.

\section{Western blot analysis}

The myeloma cells of each group were collected after U266 cells were treated with $200 \mu \mathrm{g} / \mathrm{mL}$ of each extracts and $100 \mu \mathrm{mol} / \mathrm{L}$ of monomers for $48 \mathrm{~h}$. The cells were washed with PBS, and extracted with $300 \mu \mathrm{L}$ RIPA protein extraction lysate for $30 \mathrm{~min}$ in an ice bath. The supernatant was collected by centrifuged at $13,000 \mathrm{rpm}$ at $4{ }^{\circ} \mathrm{C}$ for $10 \mathrm{~min}$. Protein extracts were separated with SDS-PAGE and transferred to PVDF membrane. After blocking, p-JAK1, JAK1, p-STAT3, STAT3 and GAPDH antibodies were added and incubated. Membranes were washed and incubated in TBST and HRP-conjugated secondary antibody, respectively. The signals were detected using the Bio-Rad ChemiDoc XRS+.

\section{UPLC/Q-TOF/MS analysis of metabolic Profling Sample preparation for LC-MS}

$1 \times 10^{7} \mathrm{U} 266$ cells were seeded in a $10 \mathrm{~cm}$ dish and exposed to $100 \mu \mathrm{g} / \mathrm{mL}$ of RXC, MYC, YDC or YDS or an equal amount of DMSO as a control. Six replicates in separate dishes for each group were analyzed. After $48 \mathrm{~h}$ incubation, cells were washed with PBS, then centrifuged and harvested. The cell pellets were rapid quenched with liquid nitrogen, then immediately dissolved in $1.0 \mathrm{~mL}$ mixture of methanol/water in ratio of $4: 1(\mathrm{v} / \mathrm{v})$ at $-20^{\circ} \mathrm{C}$ and ultra-sonicated for $30 \mathrm{~min}$ in an ice bath ultrasonicator and subsequently centrifuged to collect the supernatant. The supernatant was dried, then resuspended with $100 \mu \mathrm{L}$ of $80 \%$ methanol and filtered through $0.22 \mathrm{~mm}$ mesh millipore filters. Drawing $80 \mu \mathrm{L}$ of supernatant for LC-MS analysis. In parallel a quality control (QC) sample was prepared by mixing the leftover $20 \mu \mathrm{L}$ of supernatant from each of the 30 samples. 


\section{UPLC-Q TOF/MS conditions}

Chromatographic conditions: Acquity ${ }^{\text {ma }}$ UPLC BEH $\mathrm{C}_{18}$ column $(2.1 \mathrm{~mm} \times 50 \mathrm{~mm}, 1.7 \mu \mathrm{m})$; column temperature: $35^{\circ} \mathrm{C}$; flow rate $0.4 \mathrm{~mL} / \mathrm{min}$; injection volume: $3 \mu \mathrm{L}$; mobile phase: $0.1 \%$ formic acid water (A)-acetonitrile (B). Gradient elution conditions: 0 1 min: 5\% B, 1 3 min: 5 $\sim 50 \%$ B, 3 13 min: $50 \sim 85 \%$ B, 13 14 min: $85 \sim 95 \%$ B.

Mass spectrometry conditions: samples were ionized using an ESI ion source $\left(\mathrm{ESI}^{+} / \mathrm{ESI}^{-}\right)$with a mass scan range of 100 to $1000 \mathrm{~m} / \mathrm{z}$; capillary voltage: $3.0 \mathrm{kV}$; cone voltage: $30 \mathrm{~V}$; extraction voltage of $2.0 \mathrm{~V}$; and ion source temperature of $120^{\circ} \mathrm{C}$; desolvation gas temperature $350^{\circ} \mathrm{C}$; cone flow gas flow $50 \mathrm{~L} / \mathrm{h}$; collision energy: $20 \sim$ $50 \mathrm{eV}$; desolvation gas flow $600 \mathrm{~L} / \mathrm{h}$; activation time: 30 ms; collision gas: high purity nitrogen. A solution of 200 $\mathrm{pg} / \mathrm{mL}$ leucine- enkephalin $\left(\mathrm{ESI}^{+}: 556.2771 \mathrm{~m} / \mathrm{z}, \mathrm{ESI}^{-}\right.$: $555.2615 \mathrm{~m} / \mathrm{z}$ ) was used as the locking mass solution to ensure the accuracy during MS analysis.

\section{Metabolomics data processing and analysis}

The raw data acquired are processed using Mass Lynx software. After chromatographic peak identification, alignment and normalization, a data matrix was obtained: the mass scan range is $100-1000 \mathrm{Da}$, the retention time range is $0-15 \mathrm{~min}$, the mass deviation threshold is $0.01 \mathrm{Da}$, the mass window is $0.05 \mathrm{Da}$, the retention time window is 0.2 min, and the relative peak intensity threshold is $5 \%$, the noise cancellation level is 6.0.

In addition, based on the impurity peaks appearing in the blank solvent control sample, a list of excluded ions was prepared and introduced into the method. The final process will result in a list of data consisting of retention time, $\mathrm{m} / \mathrm{z}$ values and normalized peak areas. The data was imported into the EZ info 2.0 module for supervised partial least squares discriminant analysis (PLS-DA) and orthogonal partial least squares discriminant analysis (OPLS-DA). The Score-Plot map obtained by OPLS-DA analysis judges and displays the degree of dispersion of the metabolite profiles of samples between groups and extracts potential biomarkers. A point in OPLS-DA represents a variable. The variable importance in the projection (VIP) is measured by the value, and the variable is screened according to the VIP value. The difference between the groups was generally the normal control and the model group. This study directly compared the control group with each drug treated group.

\section{Potential biomarkers identification and metabolic pathway analysis}

Metabolites with VIP $>1$, and those with $P<0.05$ were compared between the control group compared with each drug treated group as potential biomarkers. They were input into the HMDB (http://www.hmdb.ca), firstly, the molecular weight (deviation 0.5 ) was selected, the non-endogenous was excluded, and then the relationship with the human cell metabolism was selected, and the unrelated to multiple myeloma was further deleted to obtain the difference metabolite. After the metabolites were identified, information such as the metabolite index number, molecular formula, molecular weight, retention time, VIP value, and relative expression amount were compiled into a table, and introduced into the Metabo database (http://metpa.metabolomics.ca) for metabolic pathway construction.

\section{Statistical analysis}

Data were analyzed using SPSS version 19.0. All values were expressed as the means \pm SD of at least three independently performed experiments. Statistical analyses were conducted with Student's t-test. Differences with $P<0.05$ were considered to be statistically significant. and ${ }^{*} P<0.05,{ }^{* *} P<0.01,{ }^{* * *} P<0.001$ were compared between the treatment group and the control.

\section{Results}

Determination of chemical components in frankincensemyrrh

Before investigating the anti-tumor activities of frankincense and myrrh, we analyzed the chemical components in the two drugs with the YDC and YDS as representatives. $(n=3)$. Ten components with abundant contents were detected out, and the contents in YDC was much higher in that in YDS (Table 1).

\section{Anti-proliferative activities of frankincense and myrrh on U266 cells}

RXC, MYC, at the doses of $25-400 \mu \mathrm{g} / \mathrm{mL}$, and YDC, YDS, at the doses of $12.5-400 \mu \mathrm{g} / \mathrm{mL}$, showed dosedependent anti-proliferative effects on U266 cell growth (Fig. 1). The $\mathrm{IC}_{50}$ values of $\mathrm{RXC}, \mathrm{MYC}$, YDC, YDS in

Table 1 The contents of 10 components in YDC and YDS

\begin{tabular}{lll}
\hline Components & \multicolumn{2}{l}{ Contents $(\boldsymbol{\mu g} / \mathbf{g})$} \\
\cline { 2 - 3 } & YDC & YDS \\
\hline 3-O-acetyl-boswellic acid & 30.25 & - \\
3a-acetyl-20 (29)-lupene-24-oic acid & 36.15 & 7.23 \\
$\beta$-boswellic acid & 2566.43 & 51.33 \\
acetyl 11a-methoxy- $\beta$-boswellic acid & 118.99 & - \\
3a-acetoxy-tirucall-7,24-dien-21-oic acid & 701.15 & 10.98 \\
3-acetyl-11-keto-beta-boswellic acid & 2447.87 & 40.63 \\
11-keto- $\beta$-boswellic acid & 480.12 & 10.50 \\
3-acetyl- $\beta$-boswellic acid & 765.75 & 15.30 \\
abietic acid & 6.27 & - \\
2-methoxy-8,11-epoxygermacra-1 & $10,917.79$ & 559.07 \\
(10)-7,11-trien-6-one & & \\
\hline
\end{tabular}




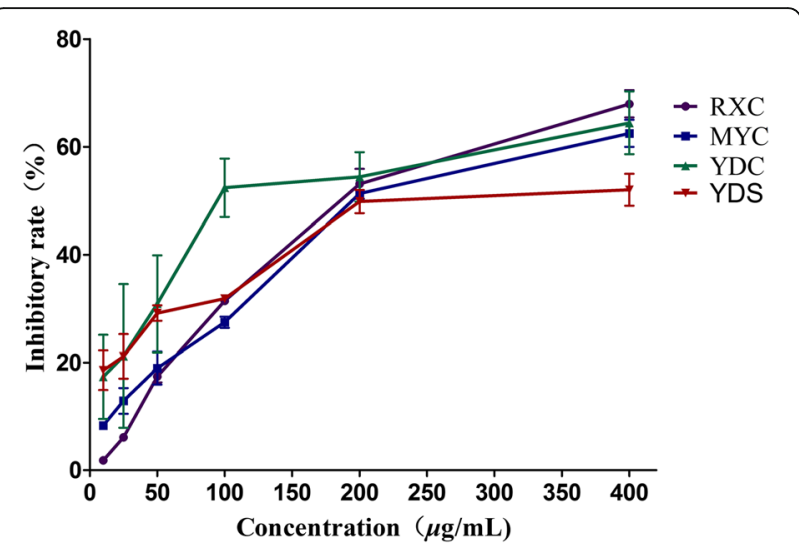

Fig. 1 Anti-proliferative effects of RXC, MYC, YDC and YDS on U266 cells. Cell viability of U266 cells analyzed by MTT assay. $P<0.05$ compared to the control group cells when the concentration is higher than $25 \mu \mathrm{g} / \mathrm{mL}$

inhibiting the growth of U266 were 194.81, 229.07, $140.68,316.75 \mu \mathrm{g} / \mathrm{mL}$, respectively.

\section{Evaluation of chemical components bioactivity}

Ten components had different degrees of inhibition effects on U266 cells proliferation. Compared with other components, 3-O-acetyl- $\alpha$-boswellic acid (BC), 3-acetyl-11 keto-boswellic acid (AKBA) and 11-ketoboswellic acid (KBA) had the most significant activities, therefore the three components were selected as representatives for Elisa assay and western blotting experiments (Table 2). The $\mathrm{IC}_{50}$ values of $\mathrm{BC}$, AKBA, KBA were $35.02,67.79,86.56 \mu \mathrm{mol} / \mathrm{L}$, respectively.

\section{Effect of frankincense and myrrh on IL-6 and VEGF secretion of U266 cells}

A significant reduction in the secretion levels of IL-6 was observed in MYC group compared to the control group, while no significant changes of the secretion levels of IL-6 was observed in other extract groups (Fig. 2a). The results were consistent with the results of $\mathrm{BC}$, AKBA, KBA (Fig. 2b). All the four extracts and active components significantly inhibited the secretion of VEGF in U266 cells (Fig. 3).

\section{Expression of JAK1, P-JAK1, STAT3 and P-STAT3}

JAK/STAT signal pathway is sustained activation status in control group cells because of the high levels expression of p-JAK1, JAK1, p-STAT3 and STAT3 proteins. Compared with control group, the expression levels of each protein were reduced to varying degrees in and U266 cells after be treated with $200 \mu \mathrm{g} / \mathrm{mL}$ RXC, MYC, YDC, YDS or $100 \mu \mathrm{mol} / \mathrm{L} \mathrm{BC}$, AKBA, KBA. Among them, AKBA had the best inhibitory effect on p-JAK1, KBA had the best therapeutic effect on JAK1, YDS had the most significant effect on p-STAT3, and MYC had a better effect on STAT3 than other treatment groups. Their relative reductions were $0.87,0.60,0.82$, and 0.40 , respectively. (Fig. 4).

\section{Metabolomics results Metabolomics analysis of RXC, MYC, YDC and YDS-treated cells}

As shown in Fig. 5a, the QC samples are tightly clustered together in PCA scores plot, indicating that there was column stability in the whole run. While there had no obvious variation of $\mathrm{QC}$ samples over all observations with respect to run order in the trend plot (Fig. 5b). Ten ions chromatographic peaks were selected to evaluated the repeatability of method through six replicates of QC samples. The relative standard deviations (RSD) of ion intensity indicated that the repeatability of method established were well (Table 3).

Table 2 Inhibition of the proliferation of U266 cells by the 10 chemical components

\begin{tabular}{|c|c|c|c|c|c|c|}
\hline \multirow[t]{2}{*}{ Components } & \multicolumn{5}{|c|}{ inhibition ratio (\%) } & \multirow{2}{*}{$\begin{array}{l}\text { IC50( } \mathrm{mol} / \\
\mathrm{L})\end{array}$} \\
\hline & $10^{-4} \mathrm{M}$ & $5 \times 10^{-5} \mathrm{M}$ & $2.5 \times 10^{-5} \mathrm{M}$ & $10^{-5} \mathrm{M}$ & $5 \times 10^{-6} \mathrm{M}$ & \\
\hline 3-O-acetyl-boswellic acid & $84.18 \pm 2.38$ & $59.22 \pm 6.41$ & $44.06 \pm 4.96$ & $11.65 \pm 0.09$ & $6.47 \pm 2.14$ & 35.02 \\
\hline 3a-acetyl-20 (29)-lupene-24-oic acid & $35.30 \pm 0.40$ & $25.11 \pm 2.76$ & $17.37 \pm 0.88$ & $13.41 \pm 1.88$ & $7.54 \pm 1.43$ & 293.20 \\
\hline$\beta$-boswellic acid & $43.68 \pm 6.75$ & $22.99 \pm 3.79$ & $20.18 \pm 0.57$ & $16.48 \pm 4.43$ & $9.22 \pm 0.44$ & 213.36 \\
\hline acetyl 11a-methoxy- $\beta$-boswellic acid & $47.66 \pm 3.84$ & $35.18 \pm 2.54$ & $31.52 \pm 6.38$ & $30.32 \pm 7.02$ & $7.45 \pm 0.95$ & 103.53 \\
\hline 3a-acetoxy-tirucall-7,24-dien-21-oic acid & $18.90 \pm 6.44$ & $8.48 \pm 1.66$ & $5.62 \pm 0.48$ & $3.91 \pm 0.79$ & $1.76 \pm 1.44$ & 665.81 \\
\hline 3-acetyl-11-keto- $\beta$-boswellic acid & $68.58 \pm 0.35$ & $39.13 \pm 10.2$ & $13.04 \pm 1.42$ & $7.42 \pm 3.56$ & $10.14 \pm 0.52$ & 67.79 \\
\hline 11-keto- $\beta$-boswellic acid & $69.62 \pm 1.56$ & $9.05 \pm 1.45$ & $7.89 \pm 10.91$ & $2.64 \pm 0.23$ & $4.17 \pm 10.46$ & 86.56 \\
\hline 3-acetyl- $\beta$-boswellic acid & $34.27 \pm 6.95$ & $26.34 \pm 2.65$ & $16.98 \pm 6.97$ & $14.24 \pm 1.84$ & $5.39 \pm 0.81$ & 267.88 \\
\hline abietic acid & $24.37 \pm 5.41$ & $18.25 \pm 4.03$ & $13.70 \pm 2.60$ & $7.52 \pm 1.27$ & $5.11 \pm 2.39$ & 643.48 \\
\hline 2-methoxy-8,11-epoxygermacra-1 (10)-7,11-trien-6-one & $27.17 \pm 3.72$ & $23.42 \pm 3.68$ & $22.74 \pm 3.71$ & $15.02 \pm 0.91$ & $11.09 \pm 4.71$ & 1411.47 \\
\hline
\end{tabular}




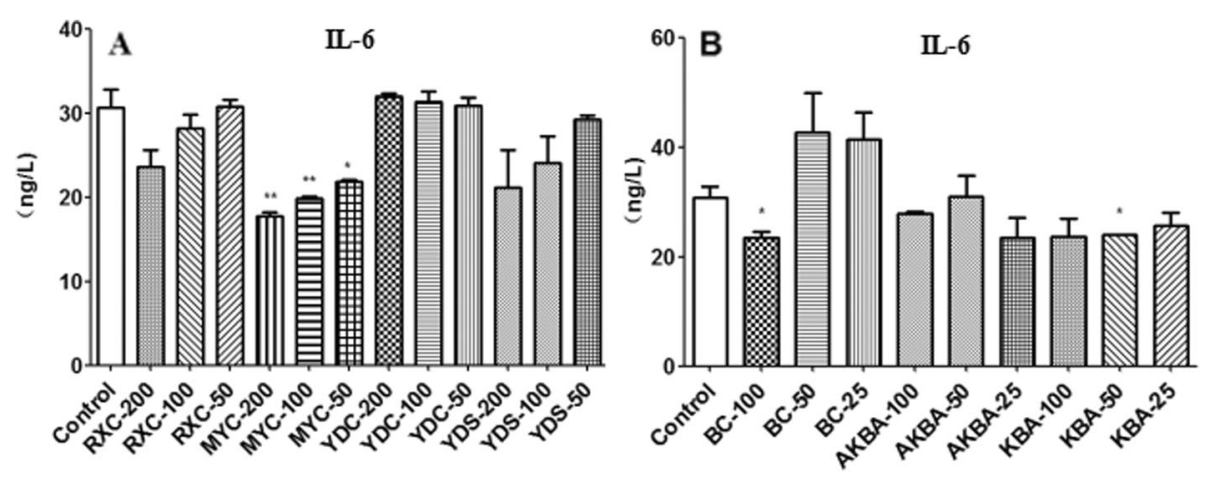

Fig. 2 The level of IL-6 secreted by U266 after be treated with extracts or active components. a RXC, MYC, YDC, YDS (50, 100 and $200 \mu \mathrm{g} / \mathrm{mL})$; b $B C, A K B A, K B A(25,50$ and $100 \mu \mathrm{mol} / \mathrm{L})$ for $48 h .{ }^{*} P<0.05,{ }^{* *} P<0.01$, vs control group $\left({ }^{-} x \pm s, n=3\right)$

Control and RXC, YDC treated groups were obviously separated along the first principal component, while control and MYC treated groups were significantly separated along the second principal component, and YDS treated group were not significantly different from the control group (Fig. 6).

\section{Identification of potential metabolic biomarkers}

The differential metabolites were screened according to the S-plot, VIP value, and inter-group peak area $t$ test between the control group and the treated groups obtained by the UPLC-QTOF/MS analysis platform. These differential metabolites identification were conducted with molecular weight, distribution and polarity of metabolite species by the Human Metabolome Database (http://hmdb.ca/). In this study, thirteen, eight, seven and seven endogenous metabolites involving in multiple metabolic pathways, such as amino acid metabolism, glucose metabolism, lipid metabolism, and vitamin metabolism etc., were ultimately identified which showed significantly changes between control and RXC, MYC, YDC, YDS groups, respectively $\left(P^{*}<0.05\right.$ or $P^{* * *}<0.01$ or $\left.P^{* * * *}<0.001\right)$ (Table 4).

\section{Metabolic pathway analysis}

A list of metabolite identifications was imported into the MetPA database, and KEGG database was searched to explore potential metabolic pathways affected by the treatment of RXC, MYC, YDC and YDS. The pathways that with an impact value above 0.10 were screened out as the potential target pathway. RXC group mainly affected the retinol metabolic pathway and the arachidonic acid metabolic pathway (Fig. 7a). MYC group mainly affected the riboflavin metabolic pathway and the phenylalanine metabolic pathway (Fig. 7b). The metabolites affected by YDC group were involved in riboflavin metabolism pathway, sphingolipid metabolism pathway, phenylalanine metabolism pathway (Fig. 7c), however there was no potential target pathway revealed in the YDS group (Fig. 7d).

\section{Discussion}

The aim of the present study was to assess the inhibitory effects of frankincense and myrrh, and try to elucidate the anti- myeloma mechanism through metabolic profiling. In this study, RXC, MYC, YDC and YDS showed dose-dependent anti-proliferative effects on U266 cell growth at the doses of $25-400 \mu \mathrm{g} /$ $\mathrm{mL}$. BC, AKBA and KBA had the most significant activities, therefore the three components were selected as representatives for Elisa assay and western blotting experiments. Studies have shown that these three components have significant antitumor activity. Park $\mathrm{B}$ et al. reported that AKBA concentrations exceeding $50 \mu \mathrm{mol} / \mathrm{L}$ in U266 cells down-regulated CXCR4 expression, which is associated with the invasion and metastasis of cancer cells [14]. Zhao W et al. showed that $\mathrm{BC}-4$ blocked the invasion and metastasis of B16F10 mouse melanoma cells by inducing differentiation and blocking the cell population in G1 phase and inhibiting topoisomerase II activity [15].

$\mathrm{MM}$ is a tumor that occurs in the terminal stage of $\mathrm{B}$ cell differentiation. Some cytokine abnormalities can affect the activation, development and differentiation of normal B cells, and play a key role in the occurrence and development of MM [16]. IL-6 is the most important cytokine to maintain MM cell survival and promote its proliferation. Tsuyama $\mathrm{N}$ et al. confirmed that MM cells expressing IL-6 have higher malignancy, faster proliferation, and are prone to drug resistance [17]. IL-6 regulates the functional status of tumor cells mainly through two signaling pathways, namely, the Rasdependent MAPK pathway, that may be associated with IL-6 proliferation of MM cells, and the Ras-independent STATs pathway, that may be associated with IL-6 

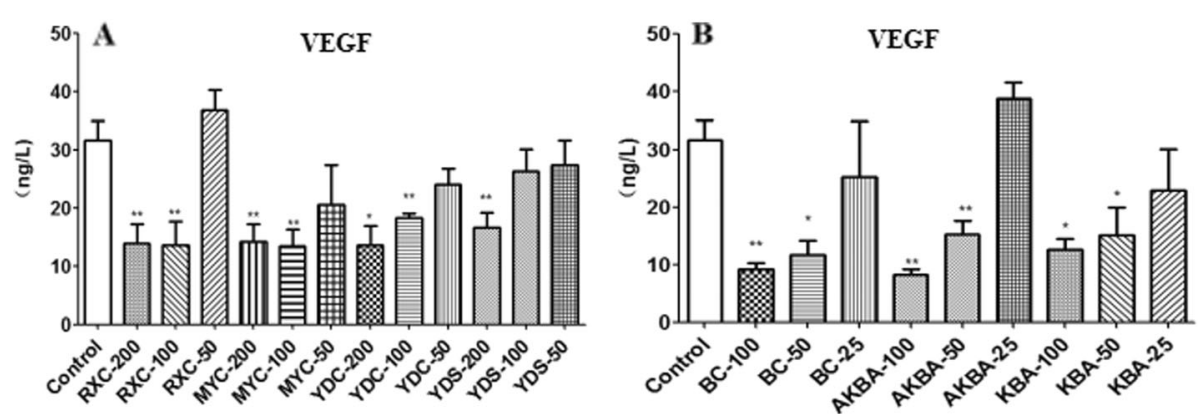

Fig. 3 The level of VEGF secreted by U266 after be treated with extracts or active components. a RXC, MYC, YDC, YDS (50, 100 and $200 \mu \mathrm{g} / \mathrm{mL}) ; \mathbf{b}$ BC, AKBA, KBA (25, 50 and $100 \mu \mathrm{mol} / \mathrm{L})$ for $48 \mathrm{~h} .{ }^{*} P<0.05,{ }^{* *} P<0.01$, vs control group $\left({ }^{-} x \pm s, n=3\right)$

inhibition of apoptosis in MM cells [18]. VEGF is a highly specific pro-vascular endothelial growth factor that promotes increased vascular permeability, extracellular matrix degeneration, vascular endothelial cell migration, proliferation, and angiogenesis [19]. MM cells promote the expression of IL- 6 in BMSCs of bone marrow stromal cells by expressing VEGF and its receptors Flt-1 and KDR, thereby promoting the proliferation of MM cells and inhibiting apoptosis [20]. In this study,
MYC significant reduced in the secretion levels of IL-6 and all the four extracts and active components significantly inhibited the secretion of VEGF in U266 cells.

We further investigated the expression levels of JAK1, P-JAK1, STAT3 and P-STAT3 to prove the cell apoptosis triggered by RXC, MYC, YDC and YDS. JAK/STAT pathway is one of the most common tumor cells apoptotic signaling pathways involving numerous cytokines, growth factors and hormones [21]. Sustained activation

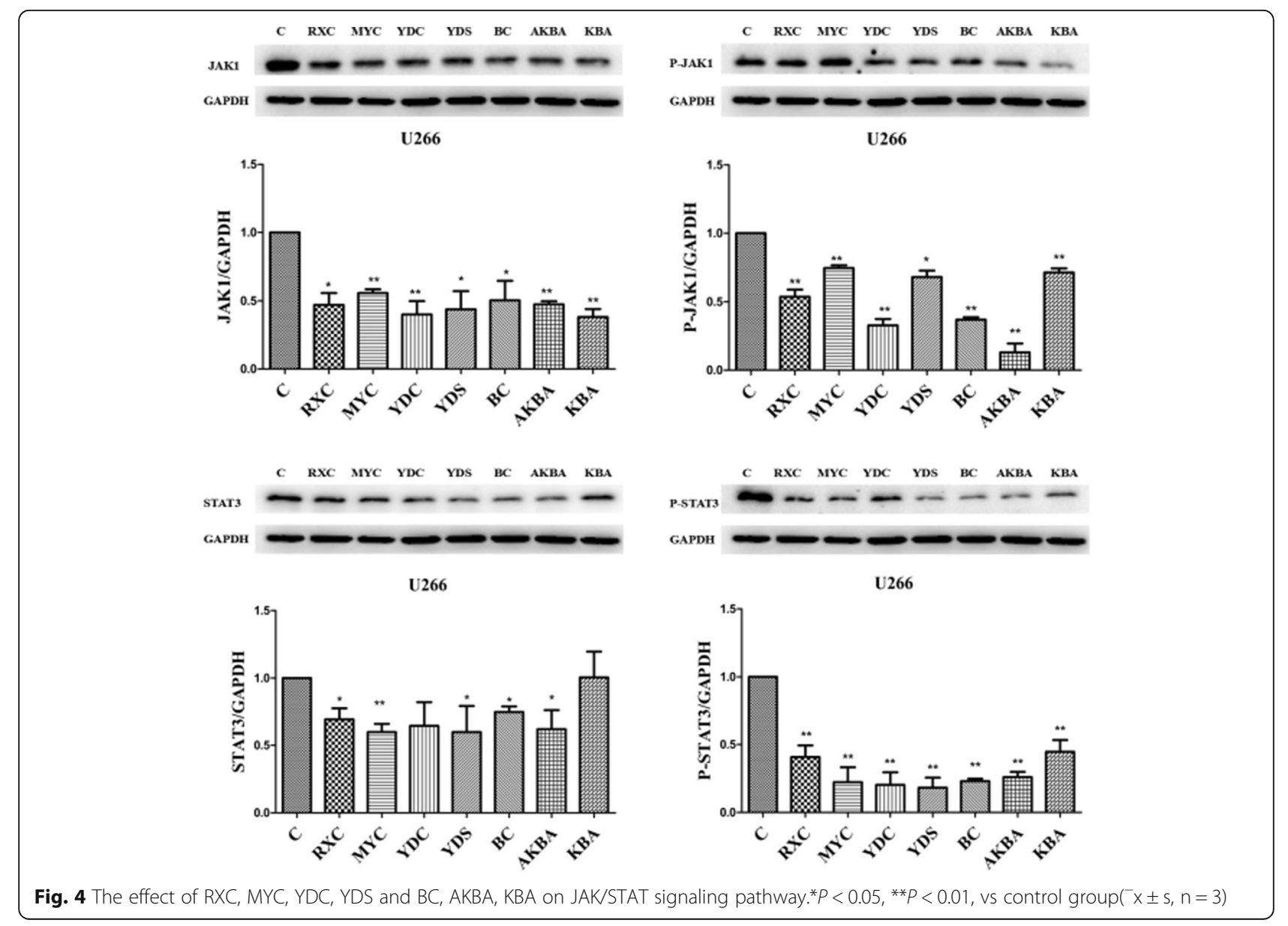




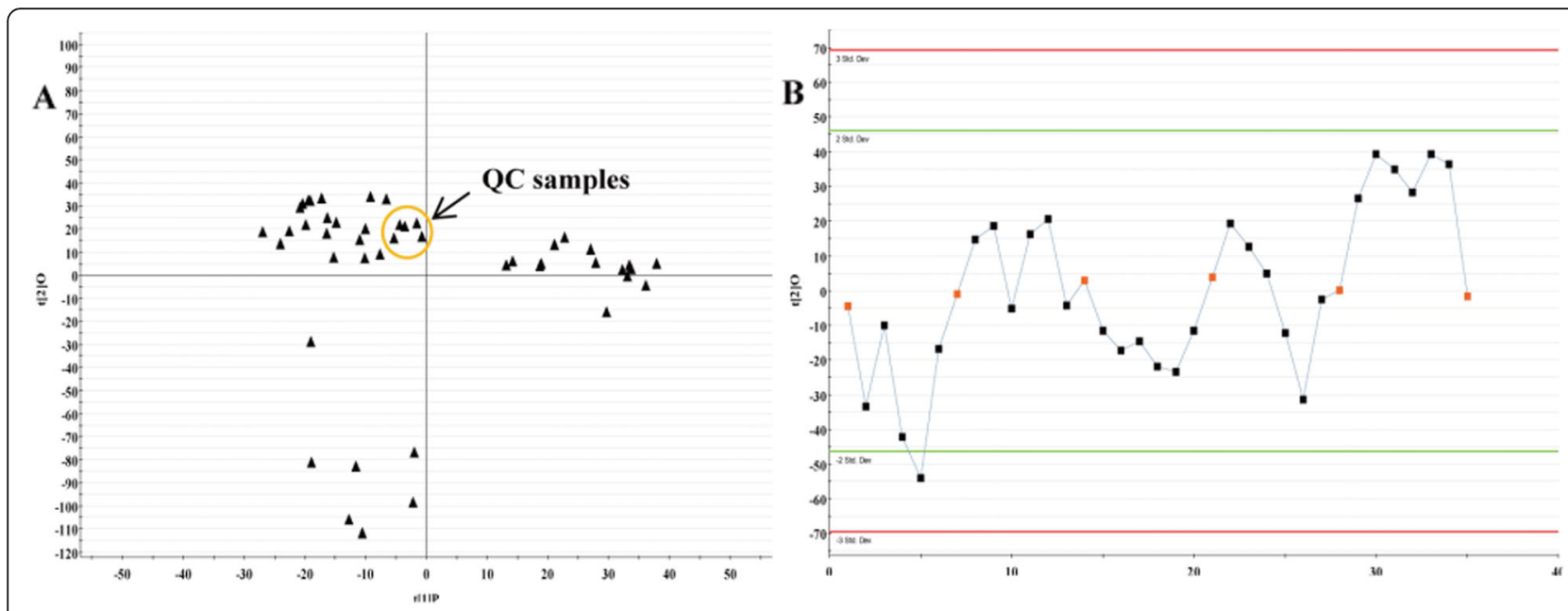

Fig. 5 Assessment of QC samples. a PCA score plot (PC1 versus PC2) of test samples and QC samples; $\mathbf{b}$ Trend plot showing the variation of $\mathrm{t}$ [1] over all observations. QC samples were colored as red boxes and test samples were colored as black triangle. $X$ axis numbers represented sample number (35 injections); $Y$ axis was arbitrary

of JAK/STAT signaling is frequently linked to cancer cell proliferation, survival, metastasis, tumor immunosuppression, and angiogenesis, and IL-6-mediated apoptosis inhibitory [22-25]. Kunnumakkara AB et al. evaluated the regulation of AKBA in U266 and MM.1S human multiple myeloma cells, SCC4 human oral squamous cells and A293 cells in vitro. The data showed that AKBA suppresses IL-6-induced STAT3 activation on those cells and phosphorylation of both Jak2 and Src. In addition, the significant inhibition of STAT3 activation by AKBA led to the suppression of gene products involved in proliferation (cyclin D1), survival (Bcl-2, Bcl$\mathrm{xL}$ and Mcl-1), and angiogenesis (VEGF) [26]. Using pSTAT3, the final link of the pathway, as a standard to evaluate the regulation effects of JAK/STAT signaling pathway by treated groups, the results showed there were significant decrease in each treated groups $(P<0.01)$, however, there was no significant difference between the extract groups.

Meanwhile, we investigated the metabolic profile of U266 cells regulated by RXC, MYC, YDC and YDS. Control and RXC, YDC treated groups were obviously separated along the first principal component, that indicated the cellular metabolic profile were significantly altered under the treatment of RXC and YDC. The results were consistent with anti-proliferative activity. The differential metabolites were screened by the UPLCQTOF/MS analysis platform. In this study, thirteen, eight, seven and seven endogenous metabolites showed significantly changes between control and RXC, MYC, YDC, YDS groups, respectively. Because the metabolites in RXC and YDC treated groups were the most significantly changed, further studies were focused on the metabolites L-homoserine, $\gamma$-glutamine putrescine and

Table 3 Variation condition of ion intensity of selected 10 ions present in the QC samples

\begin{tabular}{llllllll}
\hline$T_{\mathbf{R} \_m / z}$ pairs & QC1 & QC2 & QC3 & QC4 & QC5 & QC6 & RSD\% \\
\hline 1.48_310.1471 & 15.7756 & 16.3026 & 17.3300 & 17.9054 & 18.0781 & 17.7443 \\
2.96_437.2631 & 10.9198 & 11.1992 & 10.7915 & 12.1058 & 10.4506 & 10.9860 & 5.08 \\
3.14_525.3208 & 37.7857 & 36.6947 & 36.9523 & 38.2111 & 37.0908 & 36.6130 & 1.71 \\
5.03_242.1880 & 41.7784 & 44.1154 & 44.9999 & 45.6316 & 48.6523 & 48.6782 & 5.87 \\
6.92_376.2802 & 141.8055 & 146.5531 & 139.6780 & 140.8789 & 135.4626 & 136.0797 & 2.91 \\
7.37_194.0911 & 38.4770 & 38.8993 & 39.8244 & 40.7583 & 41.4433 & 42.1215 & 3.57 \\
8.82_233.1669 & 96.9642 & 103.5725 & 99.2803 & 92.0731 & 100.9075 & 91.6312 & 4.94 \\
9.88_250.1597 & 86.5695 & 87.7531 & 78.6450 & 85.6629 & 83.6178 & 78.3021 & 4.88 \\
10.17_311.2141 & 99.3077 & 101.6669 & 102.8994 & 105.2289 & 107.2062 & 107.9275 & 3.21 \\
13.81_116.9351 & 365.8650 & 370.4546 & 373.0977 & 373.4281 & 374.3846 & 377.9016 & 1.09 \\
\hline
\end{tabular}



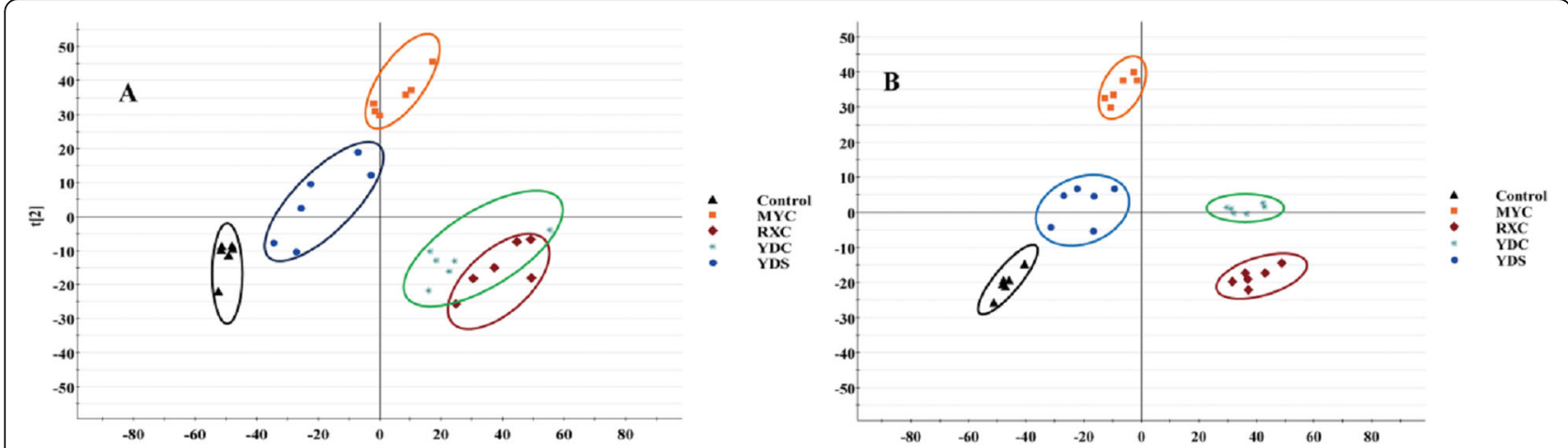

Fig. 6 PCA scores plot resulting from UPLC/MS spectra of U266 cells for control and treatment groups. a PCA scores plot in positive ion mode. $\mathbf{b}$ PCA scores plot in negative ion mode

LysoPC (18:0), and arachidonic acid metabolism, retinol metabolism, phenylalanine metabolism, riboflavin metabolism, sphingolipid metabolism and other pathways. Which altered obviously in both RXC and YDC treated groups.

Lyso-PC, derived from glycerophospholipid metabolic pathway, has been confirmed to increase oxidative stress by inducing antibody formation and stimulating macrophages, leading to lipid peroxidation and vascular endothelial dysfunction in inflammatory state [27]. Moreover, LysoPC is an intermediate product of phospholipid choline (PC) metabolism, and PC is the main lipid component of biofilm, so the change of LysoPC reflects the state of cell membrane. Compared with the control group, the content of LysoPC (18:0) was significantly increased in RXC and YDC groups, indicating that RXC and YDC can induce oxidative stress damage and destroy the stability of the cell membrane [28].

$\gamma$-glutamine putrescine is involved in the degradation pathway of putrescine II, which is formed by putrescine and L-glutamic acid driven by ATP. Putrescine is important for maintaining the basic function and viability of cells. Recent studies have found that excessive accumulation of putrescine in cells can lead to increased uptake of the medium or increased intracellular synthesis, leading to apoptosis $[29,30]$. In our study, the levels of $\gamma$-glutamine putrescine in RXC and YDC groups were significantly lower than those in the control group, indicating that RXC and YDC may block the degradation pathway of putrescine in U266 cells, and then the accumulation of $\gamma$-glutamine putrescine induce apoptosis of tumor cells.

L-homoserine is an intermediate product of methionine biosynthesis, involved in the methionine metabolic pathway. Methionine is an essential amino acid that plays an important role in protein synthesis and other biochemical processes. Studies have shown that methionine can be participate in the methylation of DNA and proteins as a methylation donor, thereby regulating the expression of genes and proteins [31]. In addition, L-methionine can inhibit the proliferation of cancer cells by inhibiting posttranslational modification of the gene p53 [32]. In the present study, the L-homoserine in RXC and YDC groups were at low levels, indicating that these two may increase the activity of methionine synthesis-related enzymes, promote the conversion of L-homoserine to methionine, and further cause methylation of U266 cell DNA, thereby inhibiting cell proliferation.

Epoxyeicosatrienoic acids (EETs) are epoxy derivative of arachidonic acid formed by cytochrome P-450 (CYP) cyclooxygenase. Cheranov et al. [33] reported that EETs induced endothelial angiogenesis by stimulating VEGF expression through Src-dependent STAT-3. Research shows 17-ODYA is an effective cycysase inhibitor, which can inhibit the expression of EETs and thus reduce the production of VEGF [34]. So, RXC and YDC may inhibition of EETS secretion on cytochrome P-450 pathway promotes apoptosis of U266 cells.

Through the above pharmacodynamic research and preliminary discussion on signal pathway and metabolic pathway, we speculate that frankincense and myrrh first inhibit the secretion of IL-6 in myeloma cells, that may affect the amount of IL- 6 in the bone marrow microenvironment. The decrease in the amount of IL- 6 causes an activation of JAK/STAT signaling pathway. Meanwhile, the stimulation of frankincense and myrrh result in the changes of metabolic pathway, thereby inhibiting tumor angiogenesis, inducing apoptosis, causing cell necrosis. The potential mechanism of frankincense and myrrh against multiple myeloma is shown in Fig. 8.

\section{Conclusions}

In summary, all of the treatment with frankincense ethanol extracts, myrrh ethanol extracts, frankincense-myrrh ethanol extracts and frankincense-myrrh water extracts 
Table 4 Potential metabolites selected and identified between treated groups and control group

\begin{tabular}{|c|c|c|c|c|c|c|c|}
\hline No. & $\mathrm{T}_{\mathbf{R}} / \mathrm{min}$ & $m / z$ & Identification & Formula & VIP & Trend & HMDB ID \\
\hline \multicolumn{8}{|c|}{ Control vs. RXC } \\
\hline 1 & 1.12 & 218.1504 & Gamma-glutamyl-L-putrescine & $\mathrm{C}_{9} \mathrm{H}_{19} \mathrm{~N}_{3} \mathrm{O}_{3}$ & 3.24 & $\downarrow$ & 12,230 \\
\hline 2 & 1.58 & 120.0872 & L-Homoserine & $\mathrm{C}_{4} \mathrm{H}_{9} \mathrm{NO}_{3}$ & 3.35 & $\downarrow$ & 00719 \\
\hline 3 & 2.42 & 203.0942 & 3-Hydroxy-N6,N6,N6-trimethyl-L-lysine & $\mathrm{C}_{9} \mathrm{H}_{21} \mathrm{~N}_{2} \mathrm{O}_{3}$ & 1.50 & $\downarrow$ & 01422 \\
\hline 4 & 2.80 & 180.0756 & Hippuric acid & $\mathrm{C}_{9} \mathrm{H}_{9} \mathrm{NO}_{3}$ & 2.35 & $\downarrow$ & 00714 \\
\hline 6 & 3.97 & 137.0335 & Urocanic acid & $\mathrm{C}_{6} \mathrm{H}_{6} \mathrm{~N}_{2} \mathrm{O}_{2}$ & 1.14 & $\uparrow$ & 00301 \\
\hline 7 & 4.64 & 192.0603 & L-Dopachrome & $\mathrm{C}_{9} \mathrm{H}_{7} \mathrm{NO}_{4}$ & 5.65 & $\downarrow$ & 01430 \\
\hline 8 & 5.25 & 181.0242 & Galactitol & $\mathrm{C}_{6} \mathrm{H}_{14} \mathrm{O}_{6}$ & 1.51 & $\downarrow$ & 00107 \\
\hline 9 & 6.52 & 448.3382 & Chenodeoxycholic acid glycine conjugate & $\mathrm{C}_{26} \mathrm{H}_{43} \mathrm{NO}_{5}$ & 2.34 & $\downarrow$ & 00637 \\
\hline 10 & 8.33 & 315.2742 & Pregnenolone & $\mathrm{C}_{21} \mathrm{H}_{32} \mathrm{O}_{2}$ & 1.55 & $\downarrow$ & 00253 \\
\hline 11 & 10.83 & 524.4035 & LysoPC(18:0) & $\mathrm{C}_{26} \mathrm{H}_{54} \mathrm{NO}_{7} \mathrm{P}$ & 3.56 & $\uparrow$ & 10,384 \\
\hline 12 & 11.93 & 305.2663 & Arachidonic acid & $\mathrm{C}_{20} \mathrm{H}_{32} \mathrm{O}_{2}$ & 1.84 & $\downarrow$ & 01043 \\
\hline 13 & 13.85 & 112.9931 & Dihydrouracil & $\mathrm{C}_{4} \mathrm{H}_{6} \mathrm{~N}_{2} \mathrm{O}_{2}$ & 2.38 & $\uparrow$ & 00076 \\
\hline \multicolumn{8}{|c|}{ Control vs. MYC } \\
\hline 1 & 1.12 & 218.1504 & Gamma-glutamyl-L-putrescine & $\mathrm{C}_{9} \mathrm{H}_{19} \mathrm{~N}_{3} \mathrm{O}_{3}$ & 3.61 & $\downarrow$ & 12,230 \\
\hline 2 & 1.57 & 120.0877 & L-Homoserine & $\mathrm{C}_{4} \mathrm{H}_{9} \mathrm{NO}_{3}$ & 2.62 & $\downarrow$ & 00719 \\
\hline 3 & 2.43 & 188.0816 & 2-Keto-6-acetamidocaproate & $\mathrm{C}_{8} \mathrm{H}_{13} \mathrm{NO}_{4}$ & 1.95 & $\downarrow$ & 12,150 \\
\hline 4 & 2.80 & 180.0759 & 2-Methyl-3-hydroxy-5-formylpyridine-4-carboxylate & $\mathrm{C}_{8} \mathrm{H}_{7} \mathrm{NO}_{4}$ & 2.06 & $\downarrow$ & 06954 \\
\hline 5 & 3.62 & 355.088 & 5-Amino-6-(5'-phosphoribitylamino)uracil & $\mathrm{C}_{9} \mathrm{H}_{17} \mathrm{~N}_{4} \mathrm{O}_{9} \mathrm{P}$ & 2.18 & $\downarrow$ & 03841 \\
\hline 6 & 4.65 & 176.0805 & Indoleacetic acid & $\mathrm{C}_{10} \mathrm{H}_{9} \mathrm{NO}_{2}$ & 1.61 & $\uparrow$ & 00197 \\
\hline 7 & 9.38 & 496.3721 & LysoPC(16:0) & $\mathrm{C}_{24} \mathrm{H}_{50} \mathrm{NO}_{7} \mathrm{P}$ & 1.96 & $\uparrow$ & 10,382 \\
\hline 8 & 9.75 & 149.0322 & trans-Cinnamic acid & $\mathrm{C}_{9} \mathrm{H}_{8} \mathrm{O}_{2}$ & 2.58 & $\uparrow$ & 00930 \\
\hline \multicolumn{8}{|c|}{ Control vs. YDC } \\
\hline 1 & 2.80 & 180.0751 & 2-Methyl-3-hydroxy-5-formylpyridine-4-carboxylate & $\mathrm{C}_{8} \mathrm{H}_{7} \mathrm{NO}_{4}$ & 1.92 & $\downarrow$ & 06954 \\
\hline 2 & 3.26 & 160.0514 & Aminoadipic acid & $\mathrm{C}_{6} \mathrm{H}_{11} \mathrm{NO}_{4}$ & 1.41 & $\downarrow$ & 00510 \\
\hline 3 & 3.62 & 355.0865 & 5-Amino-6-(5'-phosphoribitylamino)uracil & $\mathrm{C}_{9} \mathrm{H}_{17} \mathrm{~N}_{4} \mathrm{O}_{9} \mathrm{P}$ & 3.71 & $\downarrow$ & 03841 \\
\hline 4 & 3.96 & 218.2238 & Gamma-glutamyl-L-putrescine & $\mathrm{C}_{9} \mathrm{H}_{19} \mathrm{~N}_{3} \mathrm{O}_{3}$ & 2.01 & $\downarrow$ & 12,230 \\
\hline 5 & 4.00 & 171.1582 & Capric acid & $\mathrm{C}_{10} \mathrm{H}_{20} \mathrm{O}_{2}$ & 1.82 & $\uparrow$ & 00511 \\
\hline 6 & 9.72 & 149.0310 & trans-Cinnamic acid & $\mathrm{C}_{9} \mathrm{H}_{8} \mathrm{O}_{2}$ & 1.63 & $\uparrow$ & 00930 \\
\hline 7 & 10.06 & 328.2811 & Dihydroceramide & $\mathrm{C}_{19} \mathrm{H}_{39} \mathrm{NO}_{3}$ & 1.63 & $\uparrow$ & 06752 \\
\hline \multicolumn{8}{|c|}{ Control vs. YDS } \\
\hline 1 & 1.58 & 120.0869 & L-Homoserine & $\mathrm{C}_{4} \mathrm{H}_{9} \mathrm{NO}_{3}$ & 3.42 & $\downarrow$ & 00719 \\
\hline 2 & 2.43 & 188.0806 & 2-Keto-6-acetamidocaproate & $\mathrm{C}_{8} \mathrm{H}_{13} \mathrm{NO}_{4}$ & 2.87 & $\downarrow$ & 12,150 \\
\hline 3 & 2.80 & 180.0754 & 2-Methyl-3-hydroxy-5-formylpyridine-4-carboxylate & $\mathrm{C}_{8} \mathrm{H}_{7} \mathrm{NO}_{4}$ & 2.43 & $\downarrow$ & 06954 \\
\hline 4 & 3.96 & 218.2238 & Gamma-glutamyl-L-putrescine & $\mathrm{C}_{9} \mathrm{H}_{19} \mathrm{~N}_{3} \mathrm{O}_{3}$ & 2.17 & $\downarrow$ & 12,230 \\
\hline 5 & 7.47 & 460.2969 & Galactosylsphingosine & $\mathrm{C}_{24} \mathrm{H}_{47} \mathrm{NO}_{7}$ & 2.08 & $\downarrow$ & 00648 \\
\hline 6 & 10.82 & 524.4034 & LysoPC(18:0) & $\mathrm{C}_{26} \mathrm{H}_{54} \mathrm{NO}_{7} \mathrm{P}$ & 4.53 & $\uparrow$ & 10,384 \\
\hline 7 & 11.21 & 289.2684 & All-trans-13,14-dihydroretinol & $\mathrm{C}_{20} \mathrm{H}_{32} \mathrm{O}$ & 4.57 & $\uparrow$ & 11,618 \\
\hline
\end{tabular}

showed significant anti-proliferation effect on U266 cells at the dose of $25-400 \mu \mathrm{g} / \mathrm{mL}$. The inhibition effects on U266 cells proliferation of all extracts and active components were associated with the suppressed activation of JAK/STAT signaling pathways and regulation of the bone marrow microenvironment. In addition, we speculate that the proliferation inhibitory effects of U266 cells may also owe to the regulation of vitamin metabolism, amino acid metabolism and lipid metabolism. This study provides a basis for studying the mechanism of the compatibility of frankincense myrrh from the perspective of endogenous metabolites. However, the specific 

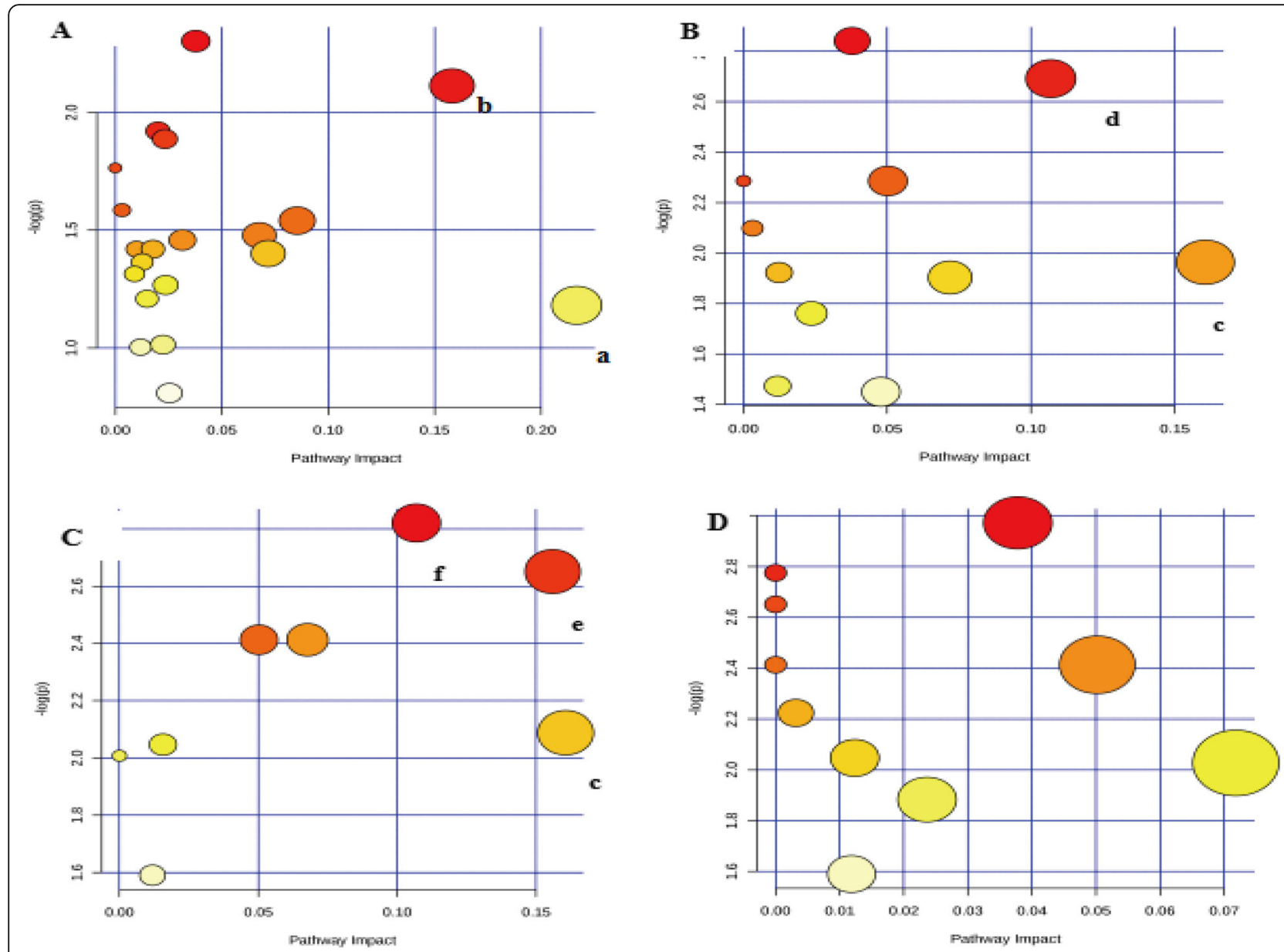

Fig. 7 Metabolic pathways constructed by differential metabolites in the RXC, MYC, YDC and YDS group. a) - $\mathbf{d}$ represented RXC, MYC, YDC and YDS groups, respectively. a Arachidonic acid metabolism, b Retinol metabolism, c Phenylalanine metabolism, d Riboflavin metabolism, e Sphingolipid metabolism

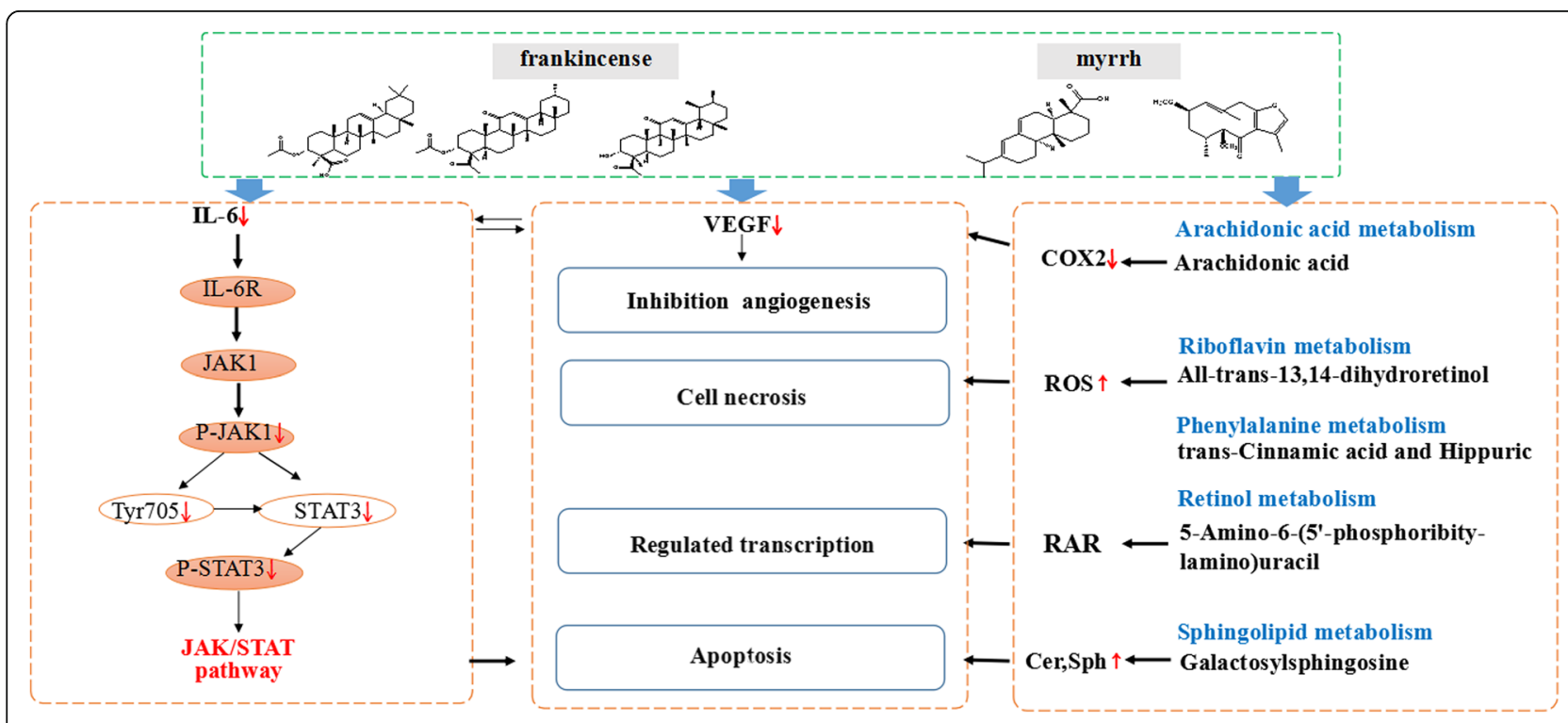

Fig. 8 The potential mechanism of frankincense and myrrh against MM 
mechanism of action remains to be determined, and there is a lack of normal control of PBMC cells and validation of metabolites in current studies. We believe that $\mathrm{PBMC/}$ in vivo toxicity and metabolite validation are necessary, and we will conduct validation tests for those in the future.

\section{Supplementary information}

Supplementary information accompanies this paper at https://doi.org/10 1186/s12906-020-2874-0

Additional file 1. Figure S1-S15 Untreated GAPDH, p-JAK1, JAK1,

p-STAT3 and STAT3 protein bands images $(n=3)$.

\begin{abstract}
Abbreviations
AKBA: 3-acetyl-11 keto-boswellic acid; BC: 3-O-acetyl-a-boswellic acid; IL-6: Interleukin-6; JAK/STAT: Janus kinase/signal transducer and activator of transcription; KBA: 11-keto-boswellic acid; MM: multiple myeloma; MTT: 3-(4,5-dimethylthizaol-2-yl)-2,5-diphenyl tetrazolium bromide; MYC: Myrrh ethanol extracts; RXC: Frankincense ethanol extracts; VEGF: Vascular endothelial growth factor; YDC: Frankincense-myrrh ethanol extracts; YDS: Frankincense-myrrh water extracts
\end{abstract}

\section{Acknowledgments}

The authors would like to thank all of the colleagues and students who contributed to this study.

\section{Authors' contributions}

GRM and MXD performed the experiments, analyzed the data and drafted the manuscript. SCJ and ZY assisted in carrying out experiments. SLS and JAD participated in the conception and design of the study. QDW and OYZ performed the statistical analysis and revised the manuscript. All authors read and approved the final version of the manuscript.

\section{Funding}

This work was supported by the National Natural Science Foundation of China (NO. 30973885; 81373889; 81973708). The funders had no role in study design, data collection and analysis, decision to publish, or preparation of the manuscript.

\section{Availability of data and materials}

Data are all contained within the manuscript.

Ethics approval and consent to participate Not applicable.

\section{Consent for publication}

Not applicable.

\section{Competing interests}

The authors declare that they have no competing interests.

\section{Author details}

${ }^{1}$ Jiangsu Collaborative Innovation Center of Chinese Medicinal Resources Industrialization, Jiangsu Key Laboratory for High Technology Research of TCM Formulae, National and Local Collaborative Engineering Center of Chinese Medicinal Resources Industrialization and Formulae Innovative Medicine, Nanjing University of Chinese Medicine, Nanjing 210023, China.

${ }^{2}$ Jiangsu University, Zhenjiang 212013, China.

Received: 21 February 2019 Accepted: 27 February 2020

Published online: 23 March 2020

\section{References}

1. Szudy-Szczyrek A, Szczyrek M, Soroka-Wojtaszko M, Hus M. New prognostic biomarkers in multiple myeloma. Postepy Hig Med Dosw. 2016;70:811-9.

2. Su S, Duan J, Chen T, Huang X, Shang E, Yu L, Wei K, Zhu Y, Guo J, Guo S. Frankincense and myrrh suppress inflammation via regulation of the metabolic profiling and the MAPK signaling pathway. Sci Rep. 2015;5(1): 13668.

3. Hu D, Wang C, Li F, Su S, Yang N, Yang Y, Zhu C, Shi H, Yu L, Geng X. A combined water extract of frankincense and myrrh alleviates neuropathic pain in mice via modulation of TRPV1. Neural Plast. 2017;2017:1-11. https:// doi.org/10.1155/2017/3710821.

4. Ruiqi W, Yan W, Zuhua G, Xianjun Q. The comparative study of acetyl-11-ketobeta-boswellic acid (AKBA) and aspirin in the prevention of intestinal adenomatous polyposis in APC (min/+) mice. Drug Discov Ther. 2014;8(1):25-32.

5. Mostafa Abbas S, Ashraf Abd-Elkhalik H. Analgesic, anti-inflammatory and anti-hyperlipidemic activities of Commiphora molmol extract (myrrh). J Intercult Ethnopharmacol. 2014;3(2):56-62.

6. Chen Y, Zhou C, Ge Z, Liu Y, Liu Y, Feng W, Li S, Chen G, Wei T. Composition and potential anticancer activities of essential oils obtained from myrrh and frankincense. Oncol Lett. 2013;6(4):1140-6.

7. Su S, Duan J, Tang Y, Zhang X, Yu L, Jiang F, Zhou W, Luo D, Ding A. Isolation and biological activities of neomyrrhaol and other terpenes from the resin of Commiphora myrrha. Planta Med. 2009;75(04):351-5..

8. Rapper S, De VSF, Van KGPP, Viljoen AM, Dagne E. The additive and synergistic antimicrobial effects of select frankincense and myrrh oils--a combination from the pharaonic pharmacopoeia. Lett Appl Microbiol. 2012;54(4):352-8.

9. Baral S, Cho DH, Pariyar R, Yoon CS, Chang BY, Kim DS, Cho HK, Kim SY, Oh $\mathrm{H}$, Kim YC. The ameliorating effect of myrrh on scopolamine-induced memory impairments in mice. Evid Based Complement Alternat Med. 2015: 2015:1-9. https://doi.org/10.1155/2015/925432.

10. Agrawal SS, Sarita S, Rajani M, Maneesha P. Antitumor properties of Boswellic acid against Ehrlich ascites cells bearing mouse. Food Chem Toxicol. 2011;49(9):1924-34.

11. Xiao-Ling W, Feng K, Tao S, Young CYF, Hong-Xiang L, Hui-Qing Y. Sesquiterpenoids from myrrh inhibit androgen receptor expression and function in human prostate cancer cells. Acta Pharmacol Sin. 2011;32(3): 338-44.

12. Yini W, Dan G, Zhe C, Shangfu L, Chunmei G, Deliang C, Feng L, Hongxia L, Yuyang J. Acridone derivative 8 a induces oxidative stress-mediated apoptosis in CCRF-CEM leukemia cells: application of metabolomics in mechanistic studies of antitumor agents. PLoS One. 2013;8(5):e63572.

13. Nicholson JK, Lindon JC, Holmes E. 'Metabonomics': understanding the metabolic responses of living systems to pathophysiological stimuli via multivariate statistical analysis of biological NMR spectroscopic data. Xenobiotica. 1999;29(11):1181-9.

14. Byoungduck P, Bokyung S, Yadav VR, Sung-Gook C, Mingyao L, Aggarwal BB. Acetyl-11-keto- $\beta$-boswellic acid suppresses invasion of pancreatic cancer cells through the downregulation of CXCR4 chemokine receptor expression. Int J Cancer. 2011;129(1):23-33.

15. Zhao W, Entschladen F, Liu H, Niggemann B, Fang Q, Zaenker KS, Han R. Boswellic acid acetate induces differentiation and apoptosis in highly metastatic melanoma and fibrosarcoma cells. Cancer Detect Prev. 2003; 27(1):67-75.

16. None: PP2-038 A review of the cytokine network in multiple myeloma: Diagnostic, prognostic and therapeutic implications. 2009, 48(1-2):1. (DOI: https://doi.org/10.1016/j.cyto.2009.07.416).

17. Abroun S, Liu S, Tsuyama N, Otsuyama KI, Ishikawa H, Zheng X, Obata M, Taniguchi O, Kawano MM, Li FJ. The Regulatory Mechanism of IL-6dependent Proliferation of Human Myeloma Cells[J]. Nephron Clinical Practice. 2003;8(6):409-11.

18. Puthier D, Bataille R, Amiot M. IL-6 up-regulates mcl-1 in human myeloma cells through JAK / STAT rather than ras / MAP kinase pathway. Eur J Immunol. 2015;29(12):3945-50.

19. Anderson $\mathrm{K}$. The vascular endothelial growth factor receptor tyrosine kinase inhibitor PTK787/ZK222584 inhibits growth and migration of multiple myeloma cells in the bone marrow microenvironment. Eur J Haematol. 2003;70(4):266-7. https://doi.org/10.1034/j.1600-0609.2003.t01-1-01067.x.

20. Klaus $P$, Anderson KC. The pathophysiologic role of VEGF in hematologic malignancies: therapeutic implications. Blood. 2005;105(4):1383-95.

21. Kisseleva T, Bhattacharya S, Braunstein J, Schindler CW. Signaling through the JAK/STAT pathway, recent advances and future challenges. Gene. 2002; 285(1):1-24.

22. Taniguchi K, Karin M. IL-6 and related cytokines as the critical lynchpins between inflammation and cancer. Semin Immunol. 2014;26(1):54-74 
23. Hua Y, Drew P, Richard J. STATs in cancer inflammation and immunity: a leading role for STAT3. Nat Rev Cancer. 2009;9(11):798-809.

24. Qing C, Eirini B, Pasquale S, Marjan B, Sizhi Paul G, Laura D, Jared W, Till T, Selena G, Xinmin Z. The IL-6/JAK/Stat3 feed-forward loop drives tumorigenesis and metastasis. Neoplasia. 2013;15(7):848-IN45. https://doi.org/10.1593/neo.13706.

25. Al-Zaid-Siddiquee T. STAT3 as a target for inducing apoptosis in solid and hematological tumors. Cell Res. 2008;18(2):254-67.

26. Kunnumakkara AB, Nair AS, Sung B, Pandey MK, Aggarwal BB. Boswellic acid blocks signal transducers and activators of transcription 3 signaling, proliferation, and survival of multiple myeloma via the protein tyrosine phosphatase SHP-1. Mol Cancer Res. 2009;7(1):118.

27. Catala A. Lipid peroxidation of membrane phospholipids generates hydroxy-alkenals and oxidized phospholipids active in physiological and/or pathological conditions. Chem Phys Lipids. 2009;157(1):1-11.

28. Wright MM, Howe AG, Vanina Z. Cell membranes and apoptosis: role of cardiolipin, phosphatidylcholine, and anticancer lipid analogues. Biochem Cell Biol. 2004;82(1):18-26. https://doi.org/10.1139/003-092.

29. Xie X, Tome ME, Gerner EW. Loss of intracellular Putrescine Pool-size regulation induces apoptosis. Exp Cell Res. 1997;230(2):386-92. https://doi. org/10.1006/excr.1996.3442.

30. Tome EM, Fiser MS, Payne MC, Gerner WE. Excess putrescine accumulation inhibits the formation of modified eukaryotic initiation factor $5 \mathrm{~A}$ (elF-5A) and induces apoptosis. Biochem J. 1997;328(Pt 3):847.

31. Laird PW. The power and the promise of DNA methylation markers. Nat Rev Cancer. 2003;3(4):253-66.

32. Benavides MA, Oelschlager DK, Huang-Ge Z, Stockard CR, Vital-Reyes VS, Katkoori VR, Upender M, Wenquan W, Bland Kl, Grizzle WE. Methionine inhibits cellular growth dependent on the p53 status of cells. Am J Surg 2007, 193(2):0-283. (DOI: https://doi.org/10.1016/j.amjsurg.2006.07.016).

33. Cheranov SY, Karpurapu M, Wang D, Zhang B, Venema RC, Rao GNL. An essential role for SRC-activated STAT-3 in 14, 15-EET-induced VEGF expression and angiogenesis. Blood. 2008;111(12):5581-91.

34. Shao J, Li Q, Wang H, Liu F, Jiang J, Zhu X, Chen Z, Zou P. P-450-dependent epoxygenase pathway of arachidonic acid is involved in myeloma-induced angiogenesis of endothelial cells. J Huazhong Univ Sci Technol. 2011;31(5): 596-601.

\section{Publisher's Note}

Springer Nature remains neutral with regard to jurisdictional claims in published maps and institutional affiliations.

Ready to submit your research? Choose BMC and benefit from:

- fast, convenient online submission

- thorough peer review by experienced researchers in your field

- rapid publication on acceptance

- support for research data, including large and complex data types

- gold Open Access which fosters wider collaboration and increased citations

- maximum visibility for your research: over $100 \mathrm{M}$ website views per year

At $\mathrm{BMC}$, research is always in progress.

Learn more biomedcentral.com/submissions 